\title{
RESONANCIAS DE AUSCHWITZ. UNA MIRADA A LO SOCIAL A PARTIR DE HENRI TAJFEL, GEORGE L. MOSSE, TONY JUDT Y ALBERT O. HIRSCHMAN
}

\author{
REVERBERATIONS OF AUSCHWITZ. HENRI TAJFEL, \\ GEORGE L. MOSSE, TONY JUDT, AND ALBERT O. \\ HIRSCHMAN AS MENTORS TO EXPLORE SOCIAL \\ REALITY
}

Martín Alonso Zarza

Bakeaz

Entregado el 8-7-2013 y aceptado el 22-1-2014.

Resumen: Este artículo rastrea el impacto del totalitarismo en la forma de entender el quehacer del científico social, con la asistencia - primordial pero no exclusiva - de cuatro reconocidos académicos: Tajfel, Mosse, Judt y Hirschman. La circunstancia del exilio como observatorio privilegiado da cuenta de un patrón de rasgos compartidos: la rebeldía frente al confinamiento identitario y disciplinar, el énfasis en la continuidad entre los procesos sociales normales y aquellos que alientan la violencia política - en particular los vinculados con la identidad - y la asunción del deber de lucidez inherente al sentimiento de vulnerabilidad y precariedad, un deber que comporta la aceptación de un rol activo en los contenciosos en que se ponen en cuestión los derechos humanos fundamentales.

Palabras clave: Totalitarismo, exilio, distancia epistémica, discriminación social, enfoque socio-moral.

Abstract: This article analyzes the impact that close experience of totalitarianism had in the role assigned to social scientists, focusing - though not exclusively - on the work of four outstanding scholars: Tajfel, Mosse, 
Judt and Hirschman. The experience of exile as a privileged lens accounts for a common pattern: resistance against the confinement through identity and discipline, emphasis on the continuity between normal social processes and those triggering political violence - particularly those linked with identity and discrimination - and assumption of a duty of lucidity inherent in the feeling of vulnerability and precariousness, a duty that implies taking an active role in disputes in which fundamental human rights are called into question.

Key words: Totalitarianism, exile, epistemic distance, social discrimination, socio-moral approach. 
Los hombres normales no saben que todo es posible. [...] La existencia de los campos es un aviso.

D. Rousset (1965: 181, 186).

«Nosotros», «los nuestros», he aquí una de las palabras clave del lenguaje estereotipado con el que se hacen las hogueras y la armazón de las guillotinas.

J. Semprún (1981: 210).

¿Para qué podía servir nuestro farisaico culto a la memoria y a los memoriales, si Estados Unidos puede construir sus propios campos de reclusión y practicar en ellos la tortura?.

T. Judt (2008b: 20).

Sofía Ósipovna constataba con estupor que, aunque el proceso de evolución había llevado millones de años, habían bastado pocos días para hacer el camino inverso, el camino que va del ser humano a la bestia sucia y miserable, desprovista de nombre y de libertad.

Grossman (2007: 242).

\section{Introducción: la pintura, la ventana, la mirada}

La intención de estas páginas es poner de relieve el interés que encierra para el análisis de la realidad social la reflexión de cuatro estudiosos procedentes de diferentes disciplinas: la Historia (Mosse y Judt), la Economía (Hirschman) y la Psicología Social (Tajfel); si bien todos ellos tienen una visión poco ortodoxa en cuanto a las fronteras de la especialización académica, acaso porque convienen con Améry (2004: 40) en la insuficiencia de las aproximaciones monocausales. ¿Qué sentido tiene escoger unos cuantos nombres para iluminar el paisaje de la ciencia social? Hay de entrada uno que remite a una peripecia vital decisiva: en todos ellos ha dejado una huella duradera la reflexión sobre el Holocausto. Ninguno pasó por los campos; no son testigos como Levi, Améry, Rousset, Antelme o Semprún, pero sí son damnificados en cuanto sus vidas se ven impactadas por el exilio. 
Para entender cabalmente su contribución es preciso mostrar la enorme diferencia en la percepción del Holocausto entre el momento de sus primeros escritos y la actualidad. Desde hace unos veinticinco años la Shoah se ha convertido en un acontecimiento central en Occidente (Bensoussan, 2011); por eso no es concebible hoy un gesto como la visita de Reagan al cementerio de Bitburg, donde yacen docenas de SS. En 1966, Améry (2004: 49) constata que los alemanes «en su mayoría aplastante no se sienten, o han dejado de sentirse, responsables de los actos... del Tercer Reich» y que por ello se dispone a contar «algunos hechos que tal vez no les habían sido aún revelados». Améry se suicida en 1978. El captó la inagotable densidad semántica del nazismo. Cuando Bauman (1992: viii) afirma que debemos considerar el Holocausto como una ventana más que como una pintura en la pared no hace sino retomar la visión de Primo Levi del campo como un observatorio privilegiado, como un «brutal laboratorio sociológico» (Markle 1999: 39). Levi, que experimentó durante años la resistencia a saber y el rechazo a sus manuscritos, se suicidó 18 años antes de que la ONU declarara el 27 de Enero como Día Internacional de las Víctimas del Holocausto. De manera que no es comparable lo que la aproximación al Holocausto supone hoy - también para las expectativas académicas - con lo que ocurría en el entusiasmo de los «treinta gloriosos». Registrar este efecto de perspectiva es de la competencia de los historiadores. Son ellos quienes, siguiendo la imagen de Bauman, deben dibujar la pintura sobre la pared. Améry nos previene (2004: 41) al respecto: «La historiografía capta sólo aspectos particulares y entre estos árboles no ve el bosque, la arboleda alemana del Tercer Reich». Hay que decir en descargo de la historiografía, en primer lugar, que la carencia no es privativa y, en segundo lugar, que su ejecutoria ha mejorado ostensiblemente desde entonces incorporando frutos de parcelas de conocimiento limítrofes. Enzo Traverso es un buen ejemplo de visión amplia; él deja sin embargo, como sin querer, un paréntesis enigmático (2012: 213): entre los exiliados comprometidos contra el nazismo «los historiadores no son numerosos».

Pero tan decisiva como el impacto de este acontecimiento histórico extremo resulta, y ese es el motivo principal de la selección, la forma de abordar una tarea intelectual construida en eco de aquel. No es fácil describirla porque no se deja apresar en las categorías académicas al uso; se trataría de una sensibilidad, de un estilo, de una actitud, de una forma de mirar. En el zurrón de nuestros mentores hay letra clara pero hay, sobre todo, una música de fondo notada en un pentagrama ético que rezuma en 
su producción intelectual y es indiferente al perímetro disciplinar. Como es arriesgado justificar un escrito en este intangible, me conforta haber encontrado esta apreciación sobre unas «afinidades electivas» no conscientes en otros estudiosos (Traverso, 2012: 229, por ejemplo). Aunque no es seguro que fueran tan inconscientes, como refleja esta observación de Tajfel tras conocer a Hirschman (1982: 20): «Charlamos sobre diversos temas y en un cierto punto descubrimos que nuestras ideas coincidían y ello sin que ninguno de los dos hubiéramos leído los escritos del otro». En una nota anterior sobre este encuentro cuenta Tajfel que después de preguntarle por el tema de la conferencia que iba a impartir, Hirschman le trajo el libro Salida, voz y lealtad, con una dedicatoria en francés, que es ella misma toda una declaración de intenciones: «Para Henri Tajfel, con el presentimiento de un diálogo» (Tajfel: 1975: 101). De manera que la coincidencia, la afinidad electiva, tiene dos anclajes: la circunstancia (el miembro objetivo que prefigura la lógica situacional) y la mirada (la reacción subjetiva que incorpora la opción, la iniciativa voluntaria del sujeto).

No hace falta decir que éste no es un ensayo ni sobre el Holocausto ni sobre el nacionalsocialismo, sino sobre una forma de mirar a la realidad social que, 1 / resulta de ese cruce de circunstancia (condición necesaria pero no suficiente, como ilustra la diversidad de respuestas) y opción, de estructura y agencia, y $2 /$ se muestra fértil para abordar el análisis de los procesos sociales en general. Los dos siguientes apartados glosan estos aspectos, las coordenadas vitales que hacen sentir sobre estas vidas el peso de un trauma sin precedentes y el impacto que, con la mediación de un estilo y una actitud, ello tiene sobre su trabajo científico; nomadismo y trashumancia disciplinar conforman esta perspectiva. El cuarto apartado trata de identificar los rasgos del estilo, de las afinidades electivas, que comparte la tétrada seleccionada a la hora de abordar su desempeño académico. El quinto se pregunta por las claves de la fecundidad de la lente de Auschwitz. El sexto se focaliza en una variable determinante, la identidad, con sus contrapartidas, la alteridad y la exclusión. En el séptimo se proyecta la lente sobre el presente para iluminar las nuevas epifanías de la exclusión. Las conclusiones traducen el cuadro impresionista precedente en orientaciones sistemáticas de interés para el análisis de la realidad social, en su acepción lata, insistiendo en la responsabilidad de la función del investigador, transversal a las disciplinas y los contextos; parodiando a Popper podría hablarse de una ética de la tarea científica. 


\section{La circunstancia: vidas prestadas, vidas transterradas}

$\mathrm{Si}$, de acuerdo con Ortega y Gasset, el devenir vital es inseparable de la circunstancia, la naturaleza extrema de la de nuestros autores se constituye en experiencia formativa determinante. El dato ineludible para el arranque - su condición de haber vivido como judíos «los periodos más siniestros de nuestro ominoso siglo» (Hirschman, 1995: 124) - marcará su trayectoria vital y, en gran medida, profesional. Mosse (1918-1999) y Hirschman (1915-2012) nacen en Berlín, Tajfel (1919-1982) en Wloclawek (Polonia) y Judt, el más joven (1948-2010), ya en el Reino Unido a donde había emigrado recientemente su familia. Todos sufren el embate del nacionalsocialismo: la familia de Mosse pierde el negocio editorial y el patrimonio inmobiliario (él no proporciona datos sobre daños personales); Hirschman (1995: 118) menciona muy de pasada la muerte de familiares y amigos en Italia; Judt (2010: 216) recibe el nombre de Tony en homenaje a Toni Avegael, prima hermana de su padre muerta en Auschwitz; H. Tajfel (cuyo nombre verdadero era Hersz Modrche), hijo de un hombre de negocios, pierde a toda su familia (Stroebe, 1982) y él escapa porque se había desplazado por razón de estudios a París - de ahí la dedicatoria en francés de Hirschman-, donde también recalarían Mosse y Hirschman; más tarde Judt por otras razones.

Sus reflexiones reflejan en formas diversas la impronta feroz del Holocausto, de manera que suscribirían la apreciación de Mosse (2000: 185, 219) cuando señala que «aunque he escrito un único libro que trata directamente sobre el Holocausto, éste figura como una presencia latente en la mayor parte de mis escritos». Hirschman, quien deja raramente traslucir la huella del horror, pone esta dedicatoria a su libro más exitoso, Salida, voz y lealtad (1977): «A Eugenio Colorni (1909-1944), quien me habló de cómo las pequeñas ideas pueden crecer». Años más tarde (1982: 15-16) ofrece nuevas pistas para esta conexión entre vida y obra en el prólogo a la edición alemana. ${ }^{1}$

¿Y cuál es la significación profunda del Holocausto? «La facilidad con la que todo un pueblo puede ser difamado, deshumanizado y destruido» (Judt, 2008a: 35). El exterminio planificado reintroduce efectivamente una etiqueta teológica - el Mal, el mal radical anticipado por Kant (Semprún, 1995: 5) y

1 «Buena parte del libro se centra en el daño que el éxodo de los portavoces potencialmente más vigorosos ocasiona sobre los restantes miembros de una comunidad [...]. Sin embargo, la inspiración última del libro tal vez se encuentre en sentimientos de culpa cuidadosamente reprimidos, que si bien resultan inadmisibles desde cualquier perspectiva racional, no por ello son menos reales» (Hirschman, 1982: 15-16). 
convertido en hilo conductor de la reflexión de H. Arendt - en la esfera política y constituye un desafío imponente para el análisis social. De ahí la relación estrecha entre las biografías seleccionadas y la producción intelectual que de sus vivencias deriva, de la continuidad entre memoria e historia. ${ }^{2} \mathrm{Se}-$ guramente el núcleo inicial de tal relación tiene que ver con una actitud que podríamos llamar de compromiso con la humanidad; lo que Heilbut (1983: 473-479) resume en frase de Brecht como el empeño de «hacer del mundo un lugar mejor». Mosse (2000: 78) y Hirschman (1995: 119) aseguran que sus escritos están animados por el activismo político; una línea que ratifican la preocupación por la cooperación internacional (Tajfel y Hirschman), el apoyo de Mosse (2000: 200) a la creación del movimiento Paz Ahora en Israel, la implicación de Judt con la disidencia de la Europa Central en el crepúsculo del socialismo real, o su denuncia del fundamentalismo del mercado, continuando en una línea que había esbozado Hirschman (1982) en sus últimos escritos. Se trata en todo caso de un compromiso universalista, una búsqueda «de ideales panhumanos» (Hirschman, 1995: 196), basada en «la fe en nuestra humanidad común» (Judt, 2010: 207) y en la «empatía por un impulso ético utópico», en palabras de Mosse (Aschheim, 1998: 11).

Para los tres que la conocen jóvenes - Judt no ha nacido aún-, la Guerra Civil española impacta en su despertar político (Mosse, 2000: 101; Tajfel, 1982: 16; Hirschman, 1995: 97; Gil Calvo, 1998: 50). ${ }^{3}$ Luego

${ }^{2}$ El lugar central que ocupa el Holocausto en el imaginario actual de Occidente nos distancia de aquellos años posteriores a la derrota de Hitler cuando las democracias exultaban de optimismo, pero pocos atendían a quienes entonces denunciaban una cesura histórica que trascendía la responsabilidad del nacionalsocialismo (Traverso, 2012: 228). El asunto tiene interés para una revista como ésta: pone de relieve la carga de historicidad (de contingencia contextual) de los conceptos y tópicos vigentes. Una búsqueda simple en Google arroja 723.000 entradas para «Holocaust Studies» (por 24.400 para «Exile Studies», para un asunto que apuntaré a continuación).

3 Por cierto, la desvinculación del golpe militar y de la dictadura franquista del bloque de estudio relativo a los totalitarismos constituye un enigma y una carencia; de esa línea se separa, junto a los hispanistas, Enzo Traverso. Desde el punto de vista interno esta anomalía tiene varias expresiones complementarias: por un lado el menguado reconocimiento de los antifascistas españoles supervivientes, - consonante con el olvido del componente anticomunista de los fascismos - y, por otro, la presencia de una corriente neorrevisionista de escaso rigor historiográfico pero apuntalada institucionalmente por algunas entradas del Diccionario Biográfico de la Real Academia de la Historia, por la posición oficial de la jerarquía católica y por el discurso negacionista (Miguez, 2014). Un proceso análogo de desconexión del fascismo ha ocurrido con las dictaduras del Cono Sur; de ahí la presencia, acompañando a nuestros protagonistas, de A. Dorfman o J. Semprún. 
Hirschman y Tajfel se incorporan a la resistencia en la Francia ocupada. El siguiente tramo de implicación se cifra en ayudar a los perseguidos por el nazismo. Tajfel trabajó en la Oeuvre de secours aux enfants, para recolocar a niños judíos huérfanos y supervivientes, una tarea, por cierto, que desplazó sus intereses intelectuales desde la química a la psicología; Hirschman (1995: 120-125, 97-99), bajo el nombre de Albert Hermant, colaboró con Varian Fry en el Emergency Rescue Committee dedicado a preparar documentación falsa para sacar a opositores al nazismo por España y Portugal, viéndose él mismo obligado a huir a finales de 1940. La producción intelectual sería, en cierto modo, una prolongación del activismo cívico, como resume Hirschman (1995: 119): «la combinación de la participación en los asuntos públicos con la apertura mental me parece constituir la base micro de una política democrática».

La apertura mental tiene que ver con lo que es la circunstancia inmediata de estos autores, que no es la vivencia extrema del Lager que narran testigos como Levi o Semprún, sino la experiencia del exilio, del transterramiento, como eco o reverberación de Auschwitz. Tal rasgo da cuenta de una constelación léxica habitada por términos como exiliado, refugiado, forastero, transeúnte, apátrida (outsiderdom, Heimatlosigkeit, statelessness, acosmia...), que denota a un humano habitante de las periferias, portador de identidades híbridas, hablante de lenguas adoptadas, reacio a dejarse enjaular en categorías de pertenencia y extremadamente vulnerable como consecuencia de la pérdida de sus adscripciones previas. Aquí me interesa destacar que la vivencia de la migración, del exilio alienta un afán de superación y una percepción de esas constricciones como aliciente: «Lejos de estar desarraigado, estoy completamente enraizado en una pluralidad de herencias en contraste» (Judt, 2010: 205); «Nunca experimenté el exilio como un conjunto de privaciones personales e intelectuales; por el contrario, el exilio me estimuló y me presentó unos desafíos que no había conocido antes», confirma Mosse (2000: 75). Tajfel (1982: 26) atribuye al hecho de haber vivido en varias culturas diferentes su pérdida de la ingenuidad. Como ha subrayado insistentemente Traverso, no se puede entender el siglo XX sin un estudio profundo de los fenómenos asociados al exilio; pero tampoco la producción literaria puede entenderse prescindiendo de esta variable que alentó en su momento la creación de un área específica de conocimiento, los estudios del exilio (Seidel, 1986: xii). El desplazamiento obligado tiene la entidad suficiente para definir una lógica situacional que prefigura pautas de conducta atribuibles a la conversión del desplazado en excluido, apátrida, paria, ser privado del de- 
recho a tener derechos, desahuciado ontológico. La experiencia del exilio es determinante para la teoría arendtiana del totalitarismo como aniquilación de la política y destrucción de la alteridad (Traverso, 2012: 240).

\section{Vidas pensadas: nomadismo identitario y distancia epistémica}

El exiliado pierde mucho, a veces tanto que la vida le resulta insoportable, como a Stephan Zweig quien se suicida en Brasil en 1942, para escándalo de Thomas Mann que le reprocha debilidad (Prochnik, 2014). Pero gana lucidez y fuerza para afirmar su voluntad frente al destino; en palabras de Judt (2010a: 226): «No podemos elegir donde comenzamos a vivir, pero podemos acabar donde queremos». No se elige la circunstancia pero se conforma el ethos, el estilo vital: son personas que se sienten nómadas transterrados, cosmopolitas agnósticos de las fronteras y refractarios a afiliaciones, pertenencias y raíces (Judt, 2010a: 206-7). Por eso mismo se muestran extremadamente desconfiados respecto a los enclaves dogmáticos. Hirschman (1995: 112, 123) recuerda cómo siendo niño le había contado decepcionado a su hermana: «Weist Du was? Vati hat keine Weltanschauung!» («iSabes una cosa? ¡Papi no tiene una concepción del mundo!»). Pensaba entonces que tener una Weltanschauung era una necesidad básica. «La subsiguiente historia de mi vida y de mi pensamiento - rectifica luego - podría ser descrita como el descubrimiento progresivo por mi parte de cuan en lo cierto había estado mi padre». La obra de Mosse (2000: 178, 185) tiene como hilo conductor los sistemas de creencias, sin reparos a la hora de admitir la propia vulnerabilidad ante sus seducciones (185). Judt (2010a: 98) ofrece una visión cáustica de este desapego hacia las creencias e identidades:

Sabía lo que significaba ser un «creyente» - pero sabía también el alto precio que se paga por una identificación tan intensa y una afiliación tan incondicional-. No había cumplido 20 años y ya había llegado a ser, sido y dejado de ser sionista, marxista y colono comunitarista [...]. A diferencia de la mayor parte de mis contemporáneos de Cambridge, estaba así inmunizado frente al entusiasmo y las seducciones de la nueva izquierda, y lo mismo a sus retoños radicales: maoísmo, gauchismo, tercermundismo, etc. [...] Era y continuo siendo desconfiado respecto a la política de la identidad en todas sus formas, judía especialmente.

Una parte de esta sensibilidad flotante se refleja en sus elecciones profesionales. En los tres mayores es visible la indecisión; Hirschman 
basculó de las ciencias políticas a la economía, Tajfel de la química a la psicología, Mosse de la literatura a la historia, una disciplina no recomendable para un judío por los escasos antecedentes (Yerushalmi, 2002: XXXII) y a la que llegó «casi por accidente» (2000: 171). Judt (2010a: 127) tuvo más claras sus preferencias: siempre quiso ser historiador, pero su manera de concebir la disciplina - como los filósofos que enseñan con ejemplos (11) - le acerca a los anteriores. La historia tiene la particularidad de servir de excipiente generalista para expresar esas sensibilidades reacias a la compartimentación y cobra un valor especial como vehículo formativo, según admite explícitamente Mosse (2000: 172). Más aún si se da una imbricación estrecha entre historia y biografía. El interés por la cultura en cuanto marco de comprensión del mundo y variable mediadora tiene que ver con ello. Tajfel (1982: 27) sostiene que aportar comprensión a los fenómenos es la tarea principal del científico y que la cuantificación no es de ningún modo un requisito indispensable. Comprensión y significación: ciencia encarnada que adquiere relevancia a la luz de la biografía y que trasciende en crítica social (Aschheim, 1998: 8).

La preferencia por las fronteras y los intersticios geográficos e intelectuales tiene su trasunto en el plano epistemológico. Cuando Bartolini (2005) asegura que Hirschman trabajó en la intersección de las ciencias sociales, describe una querencia compartida. Estos autores cruzan con igual facilidad que las geográficas las fronteras disciplinares y encuentran en esa trashumancia los alicientes para una fertilización cruzada (Hirschman, 1995: 133). Refiere Tajfel (1982: 24) en la etapa final de su vida que «a medida que crecía mi interés por ciertos aspectos de la psicología social relacionados con la política, la antropología social y la historia social», le interesaba cada vez menos «la psicología "pura"». Para él (1979: 445) los aspectos históricos, sociales y económicos de la interacción grupal tienen prioridad sobre los estrictamente psicológicos. Judt (2010a: 11) habla de una técnica impresionista consistente en trenzar lo privado con lo público, lo razonado con lo intuido, lo recordado con lo sentido. La visión de túnel, la investigación pura y el tribalismo académico están en los antípodas de la sensibilidad de estos autores. Sus trabajos se adscriben a lo que podríamos denominar una opción generalista (Heilbut, 1983: x, 476). Hay pocos precedentes de un seminario interdisciplinar como el que en 1973 abordó las implicaciones en diferentes ámbitos de Salida, voz y lealtad. Y desde luego es siempre una sorpresa constatar en los índices onomásticos el vasto territorio topográfico y disciplinar donde espigan sus referencias (para un ejemplo, Hirschman, 1995). 
Una opción epistemológica que pone el visor en las confluencias y las articulaciones tiene la ventaja de evadir los grandes escollos del reduccionismo o el unilateralismo; entre otros, el que obliga a optar entre estructura y agencia, entre gran teoría y crónica factual, entre el determinismo y el espontaneísmo, entre esencialismo y relativismo. Frente a tales posiciones nuestros autores se inclinan, como Tajfel (1982: 22), hacia los «procesos que tienen lugar entre medias» $\mathrm{y}$, como Hirschman, por las teorías de alcance medio (Hess, 1999), o las cuestiones de sentido de nivel medio (Browning, 1999: 27). De esa manera se ubican en una línea de convergencia de aportaciones de diferentes disciplinas que insisten en la interacción entre variables de distintos niveles. Recojo a continuación algunas de estas encrucijadas epistemológicas.

Desde diferentes enfoques psicosociales y sociológicos se subraya el valor de la definición de la situación. La vida humana se estructura en un doble nivel, el mundo percibido de las cosas físicas y el mundo concebido de las representaciones simbólicas. La situación que enmarca la conducta del sujeto es una «construcción significativa a partir del dato físico, construcción que engloba el mundo en el que vive y actúa el sujeto» (Nuttin, 1982: 31). Esta manera de abordar el estudio de los procesos tiene un antecedente en el enfoque new look relativo a la percepción asociado a Bruner - creador de la psicología cognitiva, judío de padre emigrante polaco y estrecho amigo de Tajfel-y sirvió de inspiración a Tajfel en sus estudios sobre el prejuicio y la categorización. Se sostiene desde aquí que no percibimos la realidad de manera neutra sino condicionada por la motivación, de modo que, en cierta medida, vemos lo que esperamos ver y tendemos a no ver lo que nos disgusta o no queremos ver (Cohen, 1982: 12; Tajfel, 1978: 304). En El gorila invisible, Ch. Chabris y D. Simons muestran hasta qué punto ciertas precondiciones puede volvernos ciegos para lo esencial (Kahneman, 2011: 23). Esto significa que para los humanos no existe lo dado puro, de modo que quienes lo invocan, como hacen con los intereses los partidarios de la teoría de elección racional, incurren en un grave error (Ross, 1997: 308). No estamos lejos de Thomas: «Lo percibido como real produce consecuencias reales»; lo que constituye a un grupo es el ser percibido como tal, como portador de tales o cuales características (Tajfel, 1975b: 379; 1982: 28).

La textura social juega un papel determinante en la definición de la situación. La mediación cultural es a la acción colectiva lo que la mediación cognitiva a la conducta individual. Aunque Mosse no se aventuró en los parajes de la psicología social, su opción por la historia cultural resulta 
consonante. La realidad es conformada por «las percepciones que los hombres y las mujeres tienen de ella, por los mitos y símbolos a través de los cuales aprehenden el mundo real. Mitos y símbolos sirven para internalizar la realidad y para infundirla miedos, deseos y esperanzas» (Mosse, 1987: 14-15; 2000: 172-173). La interacción opera entre las dos instancias: la realidad y las percepciones socialmente conformadas. Es un modelo de causalidad helicoidal, compartido de uno u otro modo por nuestros autores. De acuerdo con Tajfel (1982: 26), al reaccionar frente al propio medio de acuerdo con la pintura que de él se hace, el ser humano produce cambios en el ambiente y al cambiar el ambiente se cambia a sí mismo. No tenemos, pues, una secuencia lineal sino espiral, lo que invita a un escepticismo templado «con respecto a la formulación de leyes universales». Para Mosse (1987: 15), el foco de interés se encuentra en la «relación dialéctica entre la realidad histórica y las percepciones humanas», y tal relación «desautoriza las posiciones del determinismo crudo». Su opción metodológica aparece claramente formulada en Masses and Man: «un estudio de historia de las percepciones humanas, de las fuerzas que median entre el individuo y su mundo». Las percepciones tienen virtualidad performativa. El mundo que creó el racismo se convirtió en realidad porque el racismo lo quiso, pese a su incongruencia con los datos; «el mito aceptado como realidad se convirtió en realidad» (Aschheim, 1998: 6).

Esta aproximación está emparentada con el perspectivismo. En la tradición filosófica que va de Leibniz a Ortega, cada sujeto capta la realidad desde su propio locus, de manera que el perspectivismo representa un punto medio entre el realismo y el subjetivismo, entre el positivismo naturalista y el relativismo historicista. Desde la antropología (Wimmer y Scheller, 2003: 600) o la sociología (Markle, 1999: 38), por citar dos prismas, se constata la interdependencia entre observador y posición del observador. El foco de nuestros autores, definido por la circunstancia del exilio y la lógica situacional derivada, conforma una perspectiva fecunda que puede definirse, en palabras de Traverso en un capítulo suculento (2012: 211-249), como una «hermenéutica de la distancia». Su condición de outsiders convierte a los exiliados en sismógrafos sensibles, en analistas agudos de los males sociales; la condición de apátridas y desarraigados constituye «un observatorio privilegiado de los cataclismos». La distancia les protege en buena medida de las constricciones sociales, culturales y políticas, sigue Traverso. Entre estas constricciones cabe destacar dos emparentadas de interés para el trabajo científico: la especialización reduccionista y corporativista, por un lado, el nacionalismo metodológico, por 
otro. Su extraterritorialidad alienta una perspectiva anticonformista, intolerante con los prejuicios y estereotipos, libre de los sesgos que vehiculan las gafas de los vencedores. Traverso menciona varios ejemplos de los beneficios de la distancia. El exilio enfría el patriotismo del historiador Ernst Kantorowicz y le impulsa a revisar su forma de pensar la historia medieval, mientras que Marc Bloch, que no salió de Francia, nunca puso en cuestión su patriotismo. El exiliado se aproxima a la definición del intelectual sin ataduras que encomiaba Mannheim. En cualquier caso, el asunto de la distancia respecto al objeto de investigación es tan crucial en el terreno social que bien podría reivindicarse una suerte de proxemia epistémica. Para todas sus dimensiones, desde la emocional vinculada con la identidad, a la motivacional asociada con los intereses, es de aplicación el criterio de Upton Sinclair: «Es difícil que una persona entienda algo si su salario depende de no entenderlo». Algo tiene esto que ver con el hecho de que la mayor parte de los historiadores titulares no judíos se quedaran en Alemania y fueran, salvo excepciones como las de Gerhart Ritter y Hermann Oncken, complacientes con el nazismo (Sims, 1978).

Aquí habría que añadir un aspecto que no trata Traverso, el del nacionalismo metodológico, consistente, según Wimmer y Schiller (2003: 576), en la naturalización de la nación-estado por las ciencias sociales y perceptible en la identificación de muchos estudiosos con esa institución como unidad de referencia. Se presenta de tres maneras: ignorancia de su importancia en las sociedades modernas (algo que se aproxima a la tesis del nacionalismo banal de Billig o al tropo del gorila invisible), naturalización (dar por sentada la centralidad de la nación-estado) y la selectividad territorial (la prioridad de ciertas unidades geográficas para ciertos investigadores en el análisis de los procesos sociales). Uno podría encontrar aquí una pieza para explicar el paréntesis incómodo de Traverso sobre la infrarrepresentación de historiadores entre los intelectuales críticos: acaso existe una mayor afinidad electiva entre el historiador y el estado-nación habida cuenta del papel que desempeña como «custodio de la memoria nacional» (Sims, 1978: 248). (Recordemos el protagonismo de los historiadores en la deriva étnica serbia de fines de los noventa con su epicentro en la celebración del sexto centenario de la batalla de Kosovo o en la actual del soberanismo catalán con el tricentenario de la de 1714).

Un segundo aspecto, retomando el hilo de Traverso, apunta en otra dirección: la distancia les permitió preservar un marxismo crítico, no escolástico ni domesticado por los aparatos del socialismo real. Por oposición a los fieles y compañeros de viaje acríticos, por un lado, y a los conversos 
que trasvasaron la adhesión fanática del comunismo al anticomunismo, por otro, la distancia les permitió evadir, en buena medida, los escollos paralelos de ambos fanatismos; con las debidas cautelas para la generalización.

\section{Sísifo dichoso: estilos y sensibilidades}

De las afinidades electivas compartidas acaso la más destacada tiene que ver con una manera de afrontar la tarea intelectual, caracterizada por la suspicacia ante las ideas recibidas y la ausencia de narcisismo ante las propias. Judt (2008a: 33) aplaude a la autora de Eichmann en Jerusalén por «perturbar la paz cómoda de la opinión recibida». Tajfel se enfrentó a la asepsia de la psicología social de laboratorio practicada en EEUU y el desinterés de la disciplina por el cambio social, Mosse a las visiones dominantes sobre el origen del nazismo o a la posición de sectores de la izquierda en el periodo de Weimar, Judt tanto al bifocalismo moral de los intelectuales franceses como a la jerga de los nouveaux philosophes y Hirschman a la teoría dominante sobre el desarrollo o a la ingenuidad de las justificaciones del modelo neoliberal.

La prevención frente a las ideas recibidas tiene su contrapartida en el plano de la ética del investigador. En Grupos humanos y categorías sociales Tajfel pone en cuestión el dogma de la neutralidad del investigador social y afea la complicidad implícita de la «observación participante». No hay lugar para una comprensión de las actitudes de un grupo fascista. Con igual claridad se pronuncia Hirschman (1982: 15) en relación a los presupuestos sedicentemente asépticos de la ciencia económica. La exigencia de comprensión que obliga al historiador, volvemos a Mosse (2000: 172), no equivale a postular la omisión de juicios duros sobre eventuales objetos de estudio.

Pero esta valentía para hacer frente a posiciones bien establecidas en sus áreas de conocimiento adquiere su verdadera dimensión cuando es aplicada ad intra. No es éste un asunto tangencial para la investigación social; lo que podríamos llamar insonorización del ego epistémico es una condición necesaria para llevar a cabo el compromiso de probidad porque el sesgo autoconfirmatorio mana del narcisismo (Hirschman, 1995: 85). Pues bien, la marcada ausencia de infatuación es un rasgo compartido por los autores que comento y presumo que está emparentada con el sentimiento de vulnerabilidad, con la conciencia de vivir en cierto sentido una vida prestada (Dorfman, 1998: 60). Es el «toque berlinés» (Heilbut, 1983: 477) que canjea el pathos por ironía, la solemnidad por escepticismo y el 
egocentrismo por sutil humor antinarcisista (Traverso, 2012: 231). Escuchemos a Tafjel (1982: 32): «¿Qué fruslería lo que escribía ayer!». O a Mosse (2000: 78): «Nunca me he tomado a mi mismo ni a casi nada más con una seriedad predispuesta». En el casi nada más entra la prevención contra tres querencias dañinas: la excesiva especialización, la estandarización escolástica y la devoción a la formalización y la cuantificación de la teoría social en una especie de complejo de inferioridad respecto a las ciencias naturales (Bartolini, 2005).

Las críticas de estos autores remiten, a mi entender, a un anclaje radical en lo que podríamos denominar compromiso fundacional de las ciencias sociales: su deber referencial o de relevancia, un deber que evade la Economía dominante por el lado de la sofisticación econométrica (Petrini, 2010: 65) y otras ciencias por el de la psicomística de la identidad (Alonso, 2011). El antiesencialismo es un punto común a todos ellos y queda reflejado en esta frase recordada por Tajfel: «los grupos son procesos, no cosas» (Berreby, 2008: 206).

Pero es el autocuestionamiento el rasgo que merece el subrayado fuerte. Ya he apuntado el circuito de Judt en lo biográfico. Seguimos con Tajfel (1982: 19) cuando resume los dos tipos de actividades esenciales para la buena marcha de una disciplina científica: hacer que la investigación continúe avanzando y poner en tela de juicio la dirección en que se desarrolla. Veamos dos ejemplos de susceptibilidad a la autorrevisión. En sus últimos trabajos Mosse dio un vuelco a la tesis de La crisis de la ideología alemana en que sostenía la visión liberal de que el nazismo representaba la antítesis irracional de la modernidad burguesa (Aschheim, 1998: 7). Análogamente, al terminar de redactar Retórica de la intransigencia contra las tesis neoconservadoras, Hirschman (1991: 183; 1995: 57) se dio cuenta de que los mismos argumentos habían sido utilizados por la retórica progresista, lo que le obligó a replantear el sentido de la obra. No es la única ocasión (1995: 88-90), de modo que parece justificado el título de su trabajo más autobiográfico: A propensitity to Self-Subversion. Las páginas del capítulo 5 de esta obra son una expresión acabada de la actitud intelectual que quiere describir este apartado. Explica la resistencia a la autocrítica como una consecuencia de la inversión en autoestima asociada a las tesis por las que sus autores se han hecho famosos. El profesor de Harvard cierra este capítulo autobiográfico sirviéndose de una cita de Camus - «Hay que imaginar a Sísifo contento»- para llevar su tesis al límite: «Hay que imaginarse a Sísifo mismo haciendo rodar la roca». Se revela aquí una intuición cercana a la que formuló con tino 
Mosse (2000: 184): «Sólo se alcanza la verdadera madurez cuando uno se da cuenta de que existen problemas insolubles». En otros términos, no hay reposo para Sísifo. ${ }^{4}$

\section{El espejo de Auschwitz}

Para André Bernstein «el genocidio nazi es de algún modo central para la comprensión de nosotros mismos» (en Rosenbaum 1998: xli); entre otras cosas porque, según A Shalev, «constituye la experiencia formativa en la que ha fraguado el mundo moderno» (en Bigsby, 2006: 21). De modo que, en palabras de Mosse, «nada en la historia europea resulta ajeno al Holocausto» (en Aschheim, 1998: 6).

¿Qué ventajas proporciona una investigación al trasluz de la experiencia totalitaria? En la certera formulación de Mosse (2000: 185), el Holocausto «refleja los hilos dominantes de la cultura moderna; es como un prisma, o, mejor, como un espejo distorsionado que refleja de una forma viciada [evil] buena parte de los motivos de la gente». Para G. Agamben (1998:156), el campo de concentración es «el paradigma oculto del espacio político de la modernidad, del que tendremos que aprender las metamorfosis y los disfraces». Para Todorov (1996: 259), «debemos reconocer nuestra imagen en la caricatura que nos reflejan los campos, haciendo abstracción del grado de deformación producida».

Ahora bien, para poder establecer esa conexión diacrónica es preciso encontrar un código que permita traducir las categorías del totalitarismo a las de nuestra propia realidad. Desde una sensibilidad afilada, nuestros autores han marcado la pauta al caracterizar la «Solución final» como la expresión extrema de percepciones y procesos normales en los colectivos humanos. La extremosidad señala ese rasgo de saturación y absoluteidad del mal que representa Auschwitz, pero apunta, por el otro extremo, a la continuidad con las prácticas corrientes en la vida colectiva, como las que tienen que ver con la categorización, la exclusión y la victimación. Mosse subraya la importancia de la creación del gradiente identitario entre extraños (outsiders) y naturales (insiders) (Aschheim, 1998: 6; Mosse, 2000:

${ }^{4}$ Jean Améry, «el más sabio de los supevivientes y memorialistas», según Markle (1999:40), escribía desde su memoria torturada (2004: 46): «... iluminación no equivale a clarificación absoluta. No todo me resultaba claro cuando redacté este opúsculo, tampoco hoy me lo parece y espero que jamás me lo parezca». 
179 y 181). El exterminio nazi constituye la expresión extrema de la tendencia humana a crear imágenes estereotipadas y discriminatorias sobre los «otros» y a traducir tales percepciones y actitudes en actos (Landau, 1994: 15). Si, de acuerdo con R. Kastoryano (2010: 79), el tema del otro se encuentra en el núcleo de las preocupaciones de las ciencias sociales, entonces el nacionalsocialismo brinda una lente privilegiada.

Pero para que la lente ilumine el paisaje normal convencional es preciso desactivar una línea de interpretación que ha perdido fuelle con los años pero que sigue teniendo sus adeptos: la que subraya desde supuestos de una racionalidad normativa que el nacionalsocialismo fue una aberración histórica. Esta visión es la que ha puesto en entredicho Mosse (2000: 186). En otros términos, las abominaciones totalitarias no deben ser entendidas como una anomalía sino, en la línea de Horkheimer y Adorno (1998), en un contexto de continuidad con las dimensiones normativas de la vida cultural, social y política de la Europa postilustrada. Es la tesis de la normalidad desarrollada por Browning (1993), resumida magistralmente por P. Levi (2005: 269) y piedra de escándalo cuando Arendt la formuló por primera vez con motivo del juicio de Eichmann. El hombre nuevo del nacionalsocialismo constituía una versión extrema de la respetabilidad burguesa; en la conceptualización tardía de Mosse es el hombre de clase media corrompido que desea preservar su mundo frente a la amenaza de las fuerzas antiburguesas de la degeneración. Queda así desactivado el mecanismo de defensa que separa el nazismo de la normalidad. La persecución de minusválidos, homosexuales, gitanos, comunistas y otros asociales se inscribe en la estrategia terapéutica de la conservación de los valores de virilidad, orden, trabajo y vida familiar característicos de la respetabilidad burguesa (Aschheim, 1998: 7-9). D'Almeida (2008) ha establecido con meridiana claridad cómo los patrones de exclusión sintonizaban con las prácticas de la alta sociedad alemana.

La patología nazi responde, radicalizada, a la misma fórmula de procesos sociales normales. ${ }^{5}$ La sociedad burguesa necesita para su confort la contraparte de alteridad, el no-nosotros para la distinción (Tajfel, 1975: 379). La psicología social asegura que la diferenciación intergrupal eleva la autoes-

5 De otra manera y con más fuerza: «La frase "exterminemos a todos los salvajes" no está mas alejada del corazón del humanismo de lo que Buchenwald lo está de la casa de Goethe en Weimar» (Linqvist, 2004: 30). Al lector ubicado en el paisaje mental del nazismo no se le escapará la asociación: la relación entre Buchenwald y Goethe es un motivo recurrente en Aquel domingo (Semprún, 1991). 
tima - «no soy como ese republicano»-, tanto más cuanto más clara es la divisoria. Homogeneización intragrupal (desindividuación) y diferencia intergrupal (discriminación) son procesos interconectados. Las investigaciones de Tajfel -imprescindibles para desenvolverse en la cocina del etnonacionalismo - proporcionan una visión micro de los mismos procesos que interesan a Mosse en la escala macro. Estamos hablando de procesos psicosociales corrientes. Frente a tesis como la de la personalidad autoritaria, Tajfel puso de manifiesto que las raíces del prejuicio se encuentran en los procesos «normales» de pensamiento (Tajfel, 1975: 351; 1978: 318). El hecho mismo de la categorización es condición necesaria y suficiente para producir discriminación entre los sujetos adscritos a grupos diferentes (1975: 381), como ha puesto recurrentemente de manifiesto el denominado «paradigma del grupo mínimo». Y esto es así con independencia del fundamento objetivo de las categorías, porque éstas son construcciones culturales y políticas (Ross, 1997: 306); de modo que resulta imposible distinguir una conducta discriminatoria basada en conflictos de intereses objetivos, de aquella otra que sólo tiene sustento cognitivo o alucinatorio (Tajfel, 1978c: 441). Lo que importa es la función social a efectos de distintividad; o para decirlo con Horowitz (1985: 50): «no es el atributo lo que hace al grupo, sino el grupo y las diferencias grupales lo que convierten en importante al atributo».

\section{La identidad y sus derivas}

En suma, como sostiene R. Landau (1994: 15), el Holocausto es una manifestación de la tendencia habitual a formar estereotipos e imágenes discriminatorias sobre grupos de «otros» y convertir las actitudes derivadas en patrones de conducta. La propensión es tan habitual que bien pudiera hablarse de un universal del repertorio conductual humano (Alonso, 2011).

Precisamente, el conocimiento profundo de la fuerza negra de la historia del siglo XX se dejó sentir en las preferencias personales de muchos de estos emigrados. «Estas lealtades fervientes - a un país, a un Dios, a una idea o a un hombre - han acabado produciéndome terror», dice Judt; por eso, aún habiendo nacido y pasado buena parte de su vida en Inglaterra, (2010a: 207), «cuando pienso o hablo de los ingleses, instintivamente uso la tercera persona: no me identifico con ellos». El nacionalismo, en cuanto política de la identidad por antonomasia, ha venido siendo el marco retórico decisivo para demarcar comunidades, reivindicar derechos y legitimar ámbitos de decisión (Calhoun, 1993: 211). Y el único requisito para ello es, como se 
ha visto, que un colectivo sienta (Tajfel, 1978: 402) o imagine (Anderson, 1991) que constituye una nación. La identificación genera el proceso completo que desemboca, con las condiciones situacionales adecuadas, en el exterminio de los excluidos. Por ello, en la línea de Maalouf (1999), para Judt (2010a: 201), «"identidad” es un término peligroso. No conoce ningún uso respetable contemporáneo». ¿De dónde procede esta carga de riesgo? Recurramos a otro sociólogo nómada cuya trayectoria vital se ha cruzado en varias ocasiones con nuestros cuatro autores, R. Dahrendorf (1998: 31, 157): «Las disputas sobre la definición figuran entre los conflictos humanos más difíciles de tratar»; la exacerbación de las diferencias en los conflictos laterales o nacionales alienta la preferencia por los rasgos adscriptivos y la búsqueda romántica de la identidad en contra de la ciudadanía. Hirschman (1995: 242-248) arroja nueva luz sobre ello con una tipología que distingue entre conflictos típicos de sociedades pluralistas de mercado [...] que tienden a ser divisibles [...] y son solubles en la negociación, y aquellos, característicos de sociedades separadas por conflictos étnicos, lingüísticos o religiosos, articulados sobre la disyunción - «0...o»-y proclives a la exclusión. Hitler (1938: 237) proporciona una ilustración clarificadora: frente a los partidos políticos que se prestan a compromisos, las concepciones ideológicas jamás lo hacen y son infalibles. Razón tenía el padre de Hirschman para aborrecer las cosmovisiones.

Ciertamente es el «otro», expulsado del territorio del sujeto, el que suministra con la diferencia la identidad al grupo propio (Tajfel, 1975: 383). El exogrupo apuntala la autoestima del endogrupo a partir de lo que puede denominarse gradiente identitario. Así se entiende que la estrategia más corriente en la competición no sea la de obtener la máxima ganancia para el endogrupo sino la de maximizar la diferencia respecto al grupo elegido para la comparación (Tajfel, 1975: 380; 1979: 317); una vía para ello es la elección de Vladimir (Sidanius, Haley, Molina y Pratto, 2007) tendente a preferir el perjuicio ajeno al beneficio propio. ${ }^{6}$ De modo que se establece una correspondencia entre la satisfacción de pertenencia al grupo - para lo que se recurre a figuras como las del pueblo elegido, el destino manifiesto, el Sonderweg u otras variantes del excepcionalismo- y la profundidad del foso identitario, una relación que para lo que nos ocupa excava el abismo que separa al superhombre ario del judío subhumano. Esta visión psicosocioló-

${ }^{6}$ Cervantes recoge este refrán en El coloquio de los perros: «Que tal hay que se quiebra dos ojos porque el enemigo se quiebre uno». 
gica se reconoce en sus rasgos esenciales en la teoría política pronazi de C. Schmitt. Éste hace descansar la especificidad de lo político en la polaridad amigo-enemigo, una categorización que sirvió de patrón para erigir al judío en figura emblemática del enemigo y, como tal, cohesionador de la comunidad aria germánica en el plano interno; el enemigo es «algo extraño que debe ser negado en su viviente totalidad» (Schmitt, 1941: 166). El trayecto que une a Tajfel con Schmitt aparece resumido en la fórmula de O. Bartov (1998), también relativa al nazismo: definir enemigos es producir víctimas. Bauman (2010) ha acuñado el concepto de «asesinato categorial» para describir este proceso del que el Holocausto es expresión quintaesenciada.

El campo gravitacional creado por la fuerza de la categorización es tan enorme - Rinoceronte de Ionesco es una de sus pinturas más logradas - que alguien tan versado en las patologías del tribalismo nacionalista como Mosse (2000: 185, 191), admite que, pese al desafío que suponía a su racionalidad, no podía dejar de sentirse emocionado ante el juramento militar en las ruinas de Masada en virtud de un «lazo especial» con los compañeros de infortunio judíos (173). Su antecesor, igualmente historiador, judío y especialista en el estudio del nacionalismo, Hans Kohn, se volvió de Palestina en los años veinte cuando vio que los sionistas habían sucumbido al chauvinismo; la posición de Arendt será similar (Heilbut, 1983: 200, 417) y tanto Levi como Hessel, supervivientes del nazismo, han denunciado la deriva identitaria del Estado de Israel. Judt (2010: 99) es quien más lejos ha llevado la crítica de los males de «su» grupo de referencia. Y es que, y aquí reside la profundidad de las reflexiones de Tajfel, con independencia de las intenciones de sus formuladores, la mera enunciación de la identidad, en una ejemplificación paradigmática del principio de Thomas, produce consecuencias. Leamos para lo primero, en una especie de apostilla a Judt, a R. Kastoryano (2010: 81):

A pesar de las justificaciones políticas y teóricas del reconocimiento, cuando se afirman, reivindican y legitiman las diferencias se convierten en una fuente de paradojas [...] que convierten la política en un campo de batalla... en el cual las diferencias desembocan en la exclusión del otro.

Reconocemos el aliento schmittiano/spengleriano en la fórmula «choque de civilizaciones», un sintagma con antecedentes de prosapia. Lo usó Heidegger en 1934, poco después el cardenal Gomá en la «Carta Colectiva» tan útil para legitimar la «Cruzada», luego el partidario de la Gran Serbia, historiador y académico, Dusan Batakovic, y más tarde el ideó- 
logo fascistoide de la Liga Norte, Gianfranco Miglio antes de alcanzar el clímax con el ensayo de Huntington (1997), inspirado a su vez en el estereotipo de la alteridad orientalista de B. Lewis.?

\section{Auschwitz: entre la paideia, el deslumbramiento y el olvido}

El mayor peligro de concebir el totalitarismo nazi como la maldición del siglo sería el obsesionarnos con él hasta el extremo de volvernos ciegos a tantos males pequeños y no tan pequeños que pavimentan las avenidas del infierno cotidiano (Judt, 2008a: 34). La ciencia social no puede desentenderse de los problemas de su tiempo. Sin embargo parecería que, en una especie de movimiento pendular compensatorio, la presencia imponente de Auschwitz esté amparando la desatención a las múltiples reverberaciones del problema del mal $^{8}$ (Todorov, 1999: 278). Como han señalado, entre

7 Heidegger: «La verdadera libertad de los pueblos exige que Occidente vuelva sobre sí mismo y asegure su destino en el gran choque planetario contra los asiáticos...» (en Faye, 2009: 138). Gomá, después de definir la contienda civil como «una guerra de sistemas o de civilizaciones», señala que «ha debido llegar el momento del choque entre las dos Españas, mejor diríamos de las dos civilizaciones: la de Rusia, que no es más que una forma de barbarie, y la cristiana, de la que España había sido en siglos pasados honor y prez e invicta defensora» (en Granados, 1969: 324). Batakovic (1992: 207): «la invasión otomana en el sur de Europa señaló el comienzo de un choque de civilizaciones de cinco siglos: Europa (cristiana) y Oriente (islámico). El conflicto, que permanece vivo a día de hoy, se manifiesta en la capa más visible en el choque entre dos naciones: los serbios, en su mayoría cristianos ortodoxos, y las albaneses étnicos, mayoritariamente musulmanes». Miglio: «La Europa civilizada [occidental] debe utilizar el atavismo sanguinario de los europeos bárbaros [orientales] como muralla para detener la invasión musulmana» (Le Monde Diplomatique, enero 1994: 21). Doy por conocida la versión de Huntington (1997).

${ }^{8}$ Sólo unos ejemplos que unen estos dos extremos. En Suiza, el partido más votado en las dos últimas elecciones, la xenófoba Unión Democrática de Centro, puso en marcha una iniciativa antiminaretes que triunfó en referéndum y se ha constituido, por su derecha, un Movimiento suizo contra la islamización (Mosci) que tiene por objeto «luchar contra el fascismo y el oscurantismo islámicos» (Le Temps, 16/06/2011). El segundo ejemplo viene del testimonio de Joan Ringelheim, directora del recién inaugurado Memorial del Holocausto en EEUU, motivado por las masacres de Bosnia: «¿Cómo es que estamos construyendo un museo cuando está ocurriendo lo mismo en otro lugar? Criticamos a la gente por no hacer nada durante el Holocausto y nosotros permanecemos impasibles». Expresa su malestar en Sarajevo porque su país, mientras se enorgullecía de montar un museo al dolor pasado había mirado para otro lado y el gobierno de Clinton, intoxicado por la tesis de los fantasmas balcánicos del halcón neoconservador Robert D. Kaplan, había optado por no implicarse en Bosnia (en París, 2000: 337). 
otros, Todorov, Hessel o Judt, la experiencia totalitaria es hoy reconocible en dos dimensiones complementarias, el fanatismo étnico y el aumento de las diferencias sociales asociado a la dictadura de los mercados.

Frente a la aspiración de cosmopolitas como Zweig (2012) o Mosse (2000: 6), de vivir en un mundo sin pasaportes, sin etiquetas ni estereotipos, a la «aldea extraterritorial» que sirvió de refugio transitorio a Dorfman (1998: 98), lo que vemos en el comienzo de este nuevo siglo es un retorno, en ese mismo mundo occidental que alumbró el nazismo, de la mística de las pequeñas diferencias, de los marcadores de afiliación, de los documentos de identidad - recordemos las polémicas sobre la partida de nacimiento de Obama o sobre los años ausentes de Canadá del líder del Partido Liberal, Michael Ignatieff - , de los tests de aceptabilidad y su contrapartida, el rechazo de los extranjeros y la estigmatización de los sin-papeles (Judt, 2010a: 208). Entre las funciones de la historiografía figura la de advertir de las ominosas consecuencias de la obsesión por rastrear enemigos (Bartov, 2000: 142). Cuando empezamos categorizando al extranjero como enemigo, «cuando el dogma inexpresado se convierte en la premisa mayor de un silogismo, entonces, al final de la cadena está el Lager» (Levi, 2006: 10). ${ }^{9}$ Sin embargo la omnipresencia del Holocausto ha abocado a una «provincialización de su significación moral»; lo que equivale a perder de vista el elemento universal del problema del mal en beneficio de una apropiación particularista (Judt, 2008a: 35), que desemboca en la perversión de la gran lección en un «Nunca más a nosotros». La identificación del Holocausto con la victimización de los judíos constituía para Yehuda Elkana «la trágica y paradójica victoria de Hitler» (en Watson, 2010: 9). En vez de instrumento de análisis se convierte en fetiche. $\mathrm{Y}$ es entonces cuando el interés nacional se erige en objetivo exclusivo y excluyente, cuando Auschwitz deviene de nuevo posible (Todorov, 1996: 168). Es la victoria póstuma de Hitler, como dijo el superviviente del gueto de Varsovia M. Edelman al presenciar el horror de Srebrenica (Le Soir, 19/04/2003). Mientras rememoramos aquel horror distante levantamos nuevos muros y permanecemos insensibles ante los hundidos de las pateras, los heridos por las concertinas y los fugitivos del hambre. En aquella Italia de la que Levi presumía por su tolerancia a los extran-

${ }^{9}$ La versión española no recoge la nota aclaratoria del autor en la edición de 1973 (Einaudi, Torino, p. 13) que ilustra el proceso descrito más arriba: «El silogismo a que se hace referencia es: 'Todos los extranjeros son enemigos. Los enemigos deben ser eliminados. Todos los extranjeros deben ser eliminados». 
jeros, el particularismo ultra de la Liga Norte y el populismo de Berlusconi han resucitado los eructos de la retórica völkisch, mientras que en la ejemplar República Checa de la Carta 77 se han experimentado «tests falométricos» contra los homosexuales (El País, 15/05/2011) y un antisemitismo sin complejos vuelve a campar por el Este de Europa. La obsesión con el islamofascismo, la estigmatización del extranjero, «es una síntoma inequívoco de que hemos olvidado la lección del siglo veinte: la facilidad con que la guerra, el miedo y el dogma pueden arrastrarnos a demonizar a los otros [...] y proporcionarles tratos incalificables» (Judt 2008b: 20). La islamofobia de hoy replica el molde del antisemitismo del XIX (Traverso, 2011: 53). La lección del Holocausto anima, por el contrario, a diluir las categorizaciones identitarias, y esa es también la recomendación de $\mathrm{He}$ chter (2000: 134) y, en general, de la Psicología social. ${ }^{10}$

La dictadura de los mercados es la otra gran amenaza del momento. J. L. Sampedro y S. Hessel (2011: 13 y 26) trazan un paralelismo en la reacción: como la indignación alentó la resistencia al nazismo debe hacerlo a la tiranía de la nueva desigualdad construida por una plutocracia depredadora. Acaso los grandes logros conseguidos en términos de bienestar en los países ricos han tendido a difuminar el peso constante de esa forma de poder que se sustancia en la riqueza, con su potencial para crear desigualdad, apartheid económico y «vidas desechables», un concepto elaborado por el nacionalsocialismo (Agamben, 1998: 172-181; Traverso, 2003: 90-93) y plenamente aplicable a los desahuciados del neoliberalismo. El pensamiento cautivo de nuestro tiempo, asegura Judt (2010b: 179-180), no tiene que ver con el islamofascismo sino con la fe en el mercado derivada de supuestas leyes ineluctables del capitalismo. ${ }^{11}$ Sabemos, constata Judt (Judt, 2010b: 156), utilizando un léxico inhabitual, que una «ilimitada fe en mercados no regulados mata: la aplicación rígida del denominado "consenso de Washington" en países vulnerables [...] ha destruido millones de vidas humanas».

10 Porque, cuando entran en conflicto el nacionalismo étnico y el cívico, nacionalismo y patriotismo, suele triunfar el primero (Connor, 1994: 195), de la misma manera que las normas de exclusión categorial aplastan aquellas otras de inspiración universalista (Hardin, 1995: 141; Orwell, 1968: 419). No sólo los estudiosos, los testigos mismos de la violencia totalitaria refrendan esta tesis. Véase a título de ejemplo: Danilo Kis (1992: 338-339) o Victor Klemperer (2001: 322-323).

${ }^{11}$ En Ill Fares de Land (2010b: 91) reproduce Judt el aserto de F. Hayek, que establece la incompatibilidad entre la libertad individual y la justicia distributiva, con la conclusión implícita esperada sobre la jerarquía entre ambas. 
El desafío al paradigma económico dominante que reclama Judt no es inédito. Treinta años atrás y desde la propia ciudadela económica, Hirschman había hecho lo propio en «Ética y ciencias sociales: una tensión permanente». Allí leemos que la aceptación ciega durante tanto tiempo del paradigma de que el interés egoísta puro conduce a un «orden social no sólo aceptable, sino incluso óptimo dentro de las alternativas reales posibles» hace imperativa la contrapropuesta de que «la existencia de una ética resulta imprescindible» (1982: 10). De ahí «la reivindicación de la ética, como "insumo" imprescindible para el funcionamiento de la economía» (12). Los economistas deben incorporar a su repertorio conceptos como altruismo y benevolencia y abandonar «la postura amoral» encastrada en la figura de la Mano Invisible (13). El enfoque economicista, asentado en el paradigma del interés egoísta, ha producido enormes daños tanto en términos morales - victimación y sufrimiento social- como epistemológicos. La ética no puede ser entendida como un complemento cosmético sino que se inscribe en «la esencia misma de nuestro quehacer»; por eso los científicos sociales deben incorporarla a sus proyectos de investigación para estar «en guardia contra la posible inmoralidad de los efectos laterales de su trabajo». Este nuevo paradigma integrado constituiría una «ciencia socio-moral» (16), alternativa al amoralismo del paradigma vigente del interés egoísta y la desregulación.

En definitiva, los dos males que nos acechan remiten a lo que podría denominarse un déficit de relevancia en el desempeño de la ciencia social. El de la evasión por la vía del esencialismo de la mística identitaria, por un lado, y el del supuesto amoralismo tecnocrático-economicista, por otro. Para lo último, y puesto que este artículo presupone una cierta visión de la ciencia social, viene a pelo evocar una propuesta añeja pero vigente:

Mirando al futuro, es posible entonces visualizar una ciencia social de una naturaleza muy distinta de aquella que la mayoría de nosotros hemos conocido. Una ciencia socio-moral en la que las consideraciones éticas ya no son reprimidas o desechadas, sino, por el contrario, incorporadas sistemáticamente al razonamiento analítico, sin que una posible falta de integración suscite sentimientos de culpa. Una ciencia socio-moral en la que el tránsito entre la exhortación y el experimento se realice con fluidez y frecuencia. $\mathrm{Y}$ en la que las consideraciones morales no deban ser incorporadas de manera subrepticia ni manifestarse en forma inconsciente, sino que puedan expresarse abierta y espontáneamente. En parte, esta es la ciencia social que yo sueño con legar a nuestros nietos (Hirschman, 1982: 16-17). 
Hay un canal que comunica los dos males mayores: la radicalización identitaria sirve, por ejemplo a los populismos, para cargar sobre las espaldas de un «otro» estigmatizado las consecuencias de la tiranía de los mercados; los rigores de la Troika alimentan el cenagal de la xenofobia. Por otra parte, ambos fenómenos de exclusión comparten pareja inquina a la igualdad (Ovejero, 2011: 158).

Pero vayamos a la lección más inmediata del Holocausto. Pueden señalarse al respecto tres núcleos de relevancia. El primero y más cercano a la literalidad histórica es el que tiene que ver con la resistencia a reconocer el horror causado por los «nuestros», a considerar criminales a quienes se presentaron como salvadores de la patria, de Serbia al País Vasco, por citar dos ejemplos actuales. El segundo está relacionado con la banalización, no la banalización en el sentido de la presencia soterrada del mal normal y cotidiano, que acuñó Arendt, sino de la banalidad que deriva de un «uso abusivo, del efecto trivializador, desensibilizador de ver, decir o pensar lo mismo tantas veces que se embota la mente de la audiencia, y se torna inmune frente al mal que evocamos» (Judt, 2008a: 35). Judt (2006: 1181) recurre a Semprún para señalar las consecuencias de la desaparición de los testigos y con ella del cierre del «ciclo de la memoria activa». El miedo a la pérdida de la memoria de los supervivientes tiene que ver con el valor preventivo que se le asigna. Por eso la obsesión de todos ellos es la de no ser creídos. Es la pesadilla recurrente de P. Levi que adopta una expresión todavía más perturbadora en Semprún (1981: 56, 60, 93): el que uno mismo llegue a dudar de que el campo ha sido una realidad. El tercero conecta con la particularización del sufrimiento apuntada más arriba, por un lado, y con el efecto deslumbrador, por otro. Para lo primero, importa dejar patente que lo que une a las víctimas no es la identidad - salvo esa forma de identidad tan escasamente atendida y tan bien formulada por el también judío y exiliado recurrente, Dorfman (1998: 134), ${ }^{12}$ que es la identidad moral-, sino la dignidad; tal es la cualidad que las convierte en polo de referencia universalista de los derechos humanos. Para lo segundo, la eclosión de la memoria del Holocausto ha sido contemporánea

12 Sus abuelos huyeron de Rusia a Argentina a principios de siglo; él tuvo que hacerlo a Estados Unidos, en 1943, cuando los generales filonazis acusan a su padre de «perro judío»; la caza de brujas de McCarthy - por los años en que Stalin despliega su campaña anticosmopolita y antijudía en la que son ejecutados 13 miembros del Comité Antifascista Judío-, le devuelve a Chile de donde se exilia tras el golpe de Pinochet contra Allende un 11 de septiembre. Su libro de memorias (1998) recorre temas centrales de este artículo. 
con la implantación de una geografía del horror - villa Grimaldi, Colonia Dignidad, la Perla, la ESMA, El Olimpo, El Vesuvio, La Casita; también con nombres comunes para acentuar la banalidad: chupaderos, desaparecidos, comida para peces, grupo de tareas, ...- del mismo rubro de la «Noche y Niebla» del nazismo (Feitlowitz 1998: 49, 63) y cuyos supervivientes no sólo no han merecido un tratamiento y consideración equivalentes sino que uno de los principales asesinos, responsable de más muertes que las de ese otro 11 de septiembre tan justificadamente recordado, fue librado de la justicia por las autoridades británicas y devuelto a su país por razones humanitarias. La consagración de la impunidad. ${ }^{13}$ Precisamente para evitar los daños del deslumbramiento se han contrapeado las observaciones de nuestros protagonistas con las reflexiones de otros contextos, salidas de plumas como las de Grossman, Semprún o Dorfman, tan provechosas para el análisis social desde la concreción de las biografías respectivas y tan poderosamente sugestivas en su maestría literaria para iluminar los mecanismos psicológicos y políticos de las tiranías. Auschwitz es una referencia moral, no identitaria. La sinapsis entre la «industria del holocausto» (Novick, 1999) y el 11-S, entre el horror sin parangón del pueblo elegido y el excepcionalismo cegador de la tribu imperial (Gill, 2004: 4), han configurado una alianza ideológica de enormes consecuencias, todavía no agotadas. Contra ese monopolio identitario hay que recordar con Gill (2004: 2) y con Dorfman (2004) que hay otros Septiembres y otras Américas, que ha habido y hay otras abominaciones y otras víctimas, otros desahuciados y otras vidas sobrantes, que las reverberaciones de Auschwitz nos alcanzan.

\section{Conclusiones}

En definitiva, podría señalarse que nuestros autores interpretan lo que cabría denominar el ethos de Auschwitz o, de otro modo, un proyecto hu-

13 Desde el principio estuvo claro el protagonismo de EEUU en el golpe contra Allende. Es menos conocida la implicación indirecta a través de la formación de militares en las técnicas de guerra sucia de la Escuela de las Américas. Y ha tardado en conocerse la connivencia de Washington con la junta militar argentina (El País, 22/08/2002), responsable de unas 30.000 muertes. La monografía de la antropóloga Lesley Gill (2004) pone de manifiesto la conexión entre el adoctrinamiento ideológico, los intereses de las corporaciones multinacionales y las estrategias militares imperialistas. Samuelson (2000: 30) ve en el protagonismo en Chile de los Chicago Boys el paradigma del «fascismo de mercado». 
manístico-social que aúna compromiso personal y actividad intelectual en una fertilización cruzada de vida y pensamiento, de exploración empírica e inspiración normativa. Las líneas de fuerza de este florilegio de pedagogía pública pueden reducirse a cuatro: 1) Fuerte sensibilidad humanista en el estudio de los problemas sociales, 2) Autocuestionamiento y revisión continua de la propia reflexión, 3) Inconformismo y heterodoxia, tanto con respecto a los enfoques dominantes como a las fronteras que marcan la parcelación disciplinar, y 4) Implicación cívica en la dirección de hacer del mundo un lugar más habitable contribuyendo a remediar los males del presente, desde la percepción que expresó B. Brecht en Santa Juana de los mataderos - «¿De qué sirve saber si lo que sabéis no tiene consecuencias?»-, siguiendo la máxima de Epicuro: «Vano es el discurso del filósofo por quien no es curada ninguna afección del ser humano».

Si dirigimos la atención a las entretelas del quehacer intelectual observamos que la circunstancia del exilio, consecuencia directa del Holocausto, configura una perspectiva marcada por la distancia. La distancia intelectual favorece la crítica de las ideas recibidas, la distancia psicológica desactiva los sesgos del narcisismo y la distancia social alienta la prevención frente a las seducciones de la identidad, de las diferentes formas de nacionalismo, incluido el metodológico. Nuestros autores nos invitarían a renegar de los lirismos del Sonderweg y a adoptar la actitud opuesta, la de una memorialización asimétrica en términos identitarios (Maier, 1998: 166). La distancia sirve para manejar correctamente el espejo de Auschwitz, de modo que en vez de convertirlo en fetiche opere como instrumento capaz de iluminar las formas presentes de de victimación y sufrimiento social.

Con todo, la ventaja principal que proporciona la distancia es la amplitud de banda del campo visual. Ello nos invita a huir de los modelos simplistas de interpretación y de causación. Lo primero nos alienta a atender al doble filo de conceptos sociales como el de progreso. El segundo a evitar el encapsulamiento. Los fenómenos y problema sociales rara vez se dejan apresar por el especialismo monodiscipliar. Recíprocamente, ninguna perspectiva disciplinar puede abdicar por prurito positivista de la cuestión del sentido, de tratar de comprender, además de acumular y contrastar datos empíricos (Browning, 1999: 27). Traverso (2012: 19-21), que comparte adscripción disciplinar con Browning, no tiene reparo en reconocer la influencia subterránea y omnipresente de Walter Benjamin - cuyo suicidio en Portbou malogró su anhelado exilio - , su cuestionamiento de los presupuestos y el sentido de la historia, su reivindicación de una reconstrucción 
histórica desde el punto de vista de los vencidos — «la imagen de los antepasados sojuzgados»-, desde la premisa tan afín a nuestros protagonistas de que la historia no es solo una «ciencia» sino también «una forma de rememoración». Recogiendo el testigo, R. Koselleck (1997: 239) defiende la superioridad intelectual de la historia desde la mirada de los vencidos: «puede que la historia la escriban los vencedores, pero, a la larga, las adquisiciones históricas de conocimiento provienen de los vencidos». El estudioso se reconoce en Sísifo. Sin ilusiones, sin desesperanza.

\section{Agradecimientos}

Este texto se ha beneficiado de estímulos diversos. En primer lugar, en forma de aliento y orientación por parte de Jesús Casquete, José Ignacio Eguizabal, Milagros Gárate, Diana Mata, F. Javier Merino, Fernando Molina, Jesús María Puente y Yolanda Rouiller. En segundo lugar, en forma de sugerencias por parte de dos informantes anónimos; a ellos les debo entre otras cosas una mayor atención a la estructura y la inclusión de la perspectiva de Enzo Traverso. Ni unos ni otros son responsables de los defectos del producto ni desde luego cabe atribuírseles sintonía con la línea interpretativa del autor. Mi agradecimiento, en tercer lugar, a los editores de Historia Contemporánea por la souplesse que denota la hospitalidad para un escrito ajeno al molde canónico, a la identidad corporativa de la disciplina.

\section{Bibliografía}

ADELMAN, Jeremy (2013): Worldly Philosopher: The Odyssey of Albert O. Hirschman, Princeton University Press, New Jersey.

AGAMBEN, Giorgio (1998): Homo Sacer. El poder soberano y la nuda vida, Valencia, Pre-textos.

ALONSO, Martín (2004): Universales del odio. Creencias, emociones y violencia, Bakeaz, Bilbao.

-, (2011): «Collective Identity as a Rhetorical Device», Synthesis Philosophica, 26 (1), pp. 9-24.

AMÉRY, Jean (2004): Más allá de la expiación y de la culpa. Tentativas de superación de una víctima de la violencia, Pre-textos, Valencia.

ANDERSON, Benedict (1991): Imagined Communities. Reflections on the Origin and Spread of Nationalism, Verso, London.

ARENDT, Hannah (2004): Eichmann en Jerusalén, Debolsillo, Barcelona. 
ASCHHEIM, Steve (1999): «George Mosse at 80: A Critical Laudatio», Journal of Contemporary History, 34 (2), pp. 295-312.

BARTOLINI, Stefano (2005): «Una semblanza intelectual de Albert O. Hirschman», Breviario Político, segunda época, n. ${ }^{\circ}$ 6, mayo-junio (en línea). http//www.metapolítica.com.mx/41/breviario/mundo03.htm, acceso $20 \mathrm{de}$ mayo de 2011.

BARTOV, Omer (1998): «Defining Enemies, Making Victims: Germans, Jews and the Holocaust», American Historical Review, n. ${ }^{\circ}$ 103, pp. 71-816.

-, (2000): Mirrors of Destruction. War, Genocide, and Modern Identity, Oxford University Press, New York.

BATAKOVIC, Dusan (1992): The Kosovo Chronicles, Plato, Belgrade.

BAUMAN, Zygmunt (1992): Modernity and the Holocaust, Cornell University Press, Ithaca.

—, (2010): «El asesinato categorial. Cómo recordar el legado del siglo XX», Claves, n. ${ }^{\circ} 199$, pp. 22-31.

BENSOUSSAN, Georges (2011): ¿Auschwitz por herencia? Sobre un buen uso de la memoria, Anthropos, Barcelona.

BERREBY, David (2008): Us \& Them. The Science of Identity, The University of Chicago Press, Chicago.

BIGSBY, Christopher (2006): Remembering and Imagining. The Chain of Memo$r y$, Cambridge University Press, Cambridge.

BROWNING, Christopher R. (1993): Ordinary Men: Reserve Police Battalion 101 and the Final Solution in Poland, Harper Perennial, New York.

-, (1999): « The Holocaust and History» en P. Hayes (ed): Lessons and Legacies, Vol. III. Memory, Memorialization and Denial, North Western University Press, Evanston, pp. 23-27.

CALHOUN, Craig (1993): «Nationalism and Ethnicity», Annual Review of Sociology, n. ${ }^{\circ} 19$, pp. 211-239.

COHEN, David (1982): «Henri Tajfel», Estudios de Psicología, n. 10 , pp. 11-14.

CONNOR, Walker (1994): Ethnonationalism. The Quest for Understanding, Princeton University Press, Princeton.

DAHRENDORF, Ralf (1988): The Modern Social Conflict, Weidenfel and Nicolson, New York.

D’ALMEIDA, Fabrice (2008): Los pecados de los dioses. La alta sociedad y el nazismo, Taurus, Madrid.

DORFMAN, Ariel (1998): Rumbo al Sur, deseando el Norte, Planeta, Barcelona.

-, (1999): «Never again will a torturer shrug and walk away», The Observer, 26 de septiembre.

—, (2004): Other Septembers, Many Americas. Selected Provocations 1980-2004, Seven Stories Press, New York.

FAYE, Emmanuel (2009): Heidegger, la introducción del nazismo en la Filosofía. En torno a los seminarios inéditos de 1933-1935, Akal, Madrid. 
FEITLOWITZ, Marguerite (1998): A Lexicon of Terror. Argentine and the Legacies of Torture, Oxford University Press, New York.

GARCÍA MENÉNDEZ, José Ramón (2013): «El canón de Albert Hirschman (1915-2012) en Ciencias Sociales», Boletín Economico del ICE, n. . 3036, febrero, pp. 43-52.

GENTILE, Emilio (2007): Il fascino del persecutore. George L. Mosse e la catastrofe dell'uomo moderno, Carocci, Roma.

GIL CALVO, Enrique (1998): «Los trucos de la historia según Hirschman», Claves, n. ${ }^{\circ} 79$, pp. 50-53.

GILL, Lesley (2004): The School of the Americas. Military Training and Political Violence in the Americas, Duke University Press, Durham.

GRANADOS, Anastasio (1969). El Cardenal Gomá, primado de España, Espasa Calpe, Madrid.

GROSSMAN, Vasili (2007): Vida y destino, Galaxia Gutenberg, Barcelona.

HARDIN, Russell (1995): One for All. The Logic of Group Conflict, Princeton University Press, Princeton.

HECHTER, Michael (2000): Containing Nationalism, Oxford University Press, Oxford.

HEILBUT, Anthony (1983): Exiled in Paradise. German Refugee Artists and Intellectuals in America, from the 1930s to the Present, The Viking Press, New York.

HESS, Andreas (1999): «The 'economy of morals' and its applications - an attempt to understand some central concepts in the work of Albert O. Hirschman», Review of International Political Economy, 6 (3), pp. 338-359.

HESSEL, Stéphane (2011): ¡Indignaos! Prólogo de J.L. Sampedro, Destino, Barcelona.

HIRSCHMAN, Albert O. 1945: National Power and the Structure of Foreign Trade, University of California Press Berkeley- Los Angeles.

—, (1976): «Subdesarrollo, obstáculos a la percepción del cambio y liderismo», en D. A. Rustow (ed): Filósofos y estadistas, FCE, México, pp. 453-489.

—, (1977): Salida, voz y lealtad, FCE, México.

-, (1981): Essays in Trespassing: Economics to Politics and Beyond, Cambridge University Press New York.

—, (1982): «Ética y ciencias sociales: una tensión permanente», Colección Estudios Cieplan , n. ${ }^{\circ}$ 60, pp. 5-17.

—, (1991): Retóricas de la intransigencia, FCE, México.

-, (1995): A Propensity to Self-Subversion, Harvard University Press, Cambridge.

—, (1999): Las pasiones y los intereses, Península, Barcelona.

HITLER, Adolf (1938): Mi lucha, Editora Central del Partido Nacional Socialista, Munich.

HORKHEIMER, Max y Theodor W. Adorno (1998): Dialéctica de la Ilustración, Trotta, Madrid. 
Resonancias de Auschwitz. Una mirada a lo social a partir de Henri Tajfel,...

HOROWITZ, Donald L. (1985): Ethnic Groups in Conflict, University of California Press, Berkeley - Los Angeles.

HUNTINGTON, Samuel P. (1997): The Clash of Civilisations and The Remaking of World Order, Touschtone, London.

JUDT, Tony (2006): Postguerra. Una historia de Europa desde 1945, Taurus, Madrid.

-, (2008a): «The 'problem of evil' in Postwar Europe», The New York Review of Books, LV (2), pp. 33-35.

- , (2008b): «What Have We Learned, If Anything», The New York Review of Books, LV (7), pp. 16-20.

-, (2010a): The Memory Chalet, William Heineman, London.

-, (2010b): Ill Fares the Land, The Penguin Press, New York.

-, y Timothy Snyder (2012): Pensar el siglo XX, Taurus, Madrid.

KAHNEMAN, Daniel (2011): Thinking Fast and Slow, Allen Lane, London.

KASTORYANO, Riva (2010): «Codes of Otherness», Social Research, 7 (1), pp. 79-100.

KIS, Danilo (1992): «On Nationalism», en Mark Thompson: A Paper House, The Ending of Yugoslavia, Pantheon Books, New York, pp. 337-340.

KLEMPERER, Victor (2001): LTI. La lengua del Tercer Reich. Apuntes de un filólogo, Minúscula, Barcelona.

KOSELLECK, Reinhart (1997): L'expérience de l'histoire, Gallimard/Seuil/Hautes Études, París.

LANDAU, Ronnie S. (1994): The Nazi Holocaust, Ivan R. Dee, Chicago.

LEVI, Primo (2005): Los hundidos y los salvados, El Aleph, Barcelona.

-, (2006): Si esto es un hombre, El Aleph, Barcelona.

LINQVIST, Sven (2004): «Exterminad a todos los salvajes», Turner, Madrid.

MAALOUF, Amin (1999): Identidades asesinas, Alianza, Madrid.

MAGRIS, Claudio (2001): Microcosmi, Garzanti, Milano.

MAIER, Charles S. (1997): The Unmasterable Past. History, Holocaust, and German National Identity, Harvard University Press, Cambridge, Mass.

MARKLE, Gerald E. (1999): «The Holocaust and Sociology», en P. Hayes (ed): Lessons and Legacies, Vol. III. Memory, Memorialization and Denial, North Western University Press, Evanston, pp. 33-40.

MCPHERSON, Michael S. (2000): «Albert O. Hirschman», en Philip Arestis y Malcolm Sawyer (eds.): A Biographical Dictionary of Dissenting Economist, Edward Elgar, Chetelham.

MELDOLESI, Luca (1995): Discovering the Possible: The Surprising World of Albert O. Hirschman, University of Notre Dame Press, Notre Dame.

MIGUEZ, Antonio. 2014. La genealogía genocida del franquismo. Violencia, memoria e impunidad, Abada, Madrid.

MOSSE, George L. (1987): Masses and Man. Nationalist and Fascist Perceptions of Reality, Wayne State University Press, Detroit.

—, (1997): La cultura europea del siglo XX, Ariel, Barcelona. 
—, (2000): Confronting History. A Memoir, The University of Wisconsin Press, Madison.

NOVICK, Peter (1999): The Holocaust in American Life, Houghton Mifflin, Boston.

NUTTIN, Joseph (1982): Teoría de la motivación humana, Paidós, Barcelona.

ORTEGA Y GASSET, José (1983): ¿Qué es filosofía?, Tomo VII de Obras Completas, Alianza, Madrid.

ORWELL, George (1968): «Notes on Nationalism», en The Collected Essays, Journalism and Letters, Vol. 3. As I Please 1943-1945, Penguin, Harmmondsworth, pp. 410-430.

OUMMIA Dianne R. y Stanislav Pejsa (2003): Guide to the Papers of George L. Mosse (1918-1999), 1780-2001, New York, Leo Baeck Institute, http://findingaids.cjh.org/?pID=121473, acceso 20 de junio de 2011 .

OVEJERO, Félix (2011): La trama estéril. Izquierda y nacionalismo, Montesinos, Barcelona.

PARIS, Erna. (2000): Long Shadows. Truth, Lies and History, Bloomsbury, New York.

PETRINI, Roberto (2010): Proceso a los economistas, Alianza, Madrid.

PROCHNIK, George (2014). The impossible Exile: Stefan Zweig and the End of the World, The Other Press, New York.

REICHER, Steven (2006): Biography of Henri Tajfel (en línea). http://easp.org. eu/activities/own /awards/tajfel.htm, acceso 25 de mayo de 2011.

ROSENBAUM, Ron (1998): Explaining Hitler. The Search for the Origins of His Evil, Macmillan, London.

ROSS, Marc Howard (1997): «The Relevance of Culture for the Study of Political Psychology and Ethnic Conflict», Political Psychology, 18 (2), pp. 299-326.

ROUSSET, David (1965): L'Univers concentrationnaire, Minuit, París.

SAMUELSON, Paul (2000): «La economía mundial a finales de siglo», Ciencia Ergo Sum 7 (1), pp. 19-30.

SCHMITT, Carl (1941). Estudios políticos (La época de la neutralidad, Teología política, El concepto de la política), Cultura Española, Madrid.

SEMPRÚN, Jorge (1981): Aquel domingo, Planeta, Barcelona.

-, (1995): Mal et modernité, Climats, París.

SEIDEL, Michael (1986): Exile and the Narrative Imagination, Yale University Press, New Haven.

SIDANIUS, Jim, Hillary Haley, Ludwin Molina y Felicia Pratto (2007): «Vladimir's choice and the distribution of social resources: A group dominance perspective», Group Processes \& Intergroup Relations 10 (2), pp. 257265.

SIMS, Amy R. (1978): «Intellectuals in Crisis: Historians Under Hitler», The Virginian Quarterly Review, 54 (2), pp. 246-262. 
STROEBE, Wolfgang (1982): «Henri Tajfel (1919-1982)», European Journal of Social Psychology, 12 (2), pp. i-iii.

TAJFEL, Henri (1975): «The exit of social mobility and the voice of social change: Notes on the social psychology of intergroup relations», Social Science Information, 14 (2), pp. 101-118.

—, (1975b): «La categorización», en S. Moscovici (dir.), Introducción a la Psicología Social, Planeta, Barcelona, pp. 349-388.

-, (1978a): «The Structure of our Views about Society», en H. Tajfel y C. Fraser (eds.), Introducing Social Psychology, Penguin, Harmondsworth, pp. 302-321.

-, (1978b): «Intergroup Behaviour I. Individualistic Perspectives», en H. Tajfel y C. Fraser (eds.), O.C., pp. 401-422.

-, (1978c): «Intergroup Behaviour II. Group Perspectives», en H. Tajfel y C. Fraser (eds.), O.c., pp. 423-446.

-, (1982): «Entrevista con H. Tajfel» (por David Cohen), Estudios de Psicología, n. ${ }^{\circ} 10$, pp. 16-32.

-, (1984): Grupos humanos y categorías sociales, Herder, Barcelona.

TAJFEL, Henry y Colin Fraser (1978): «Social Psychology as Social Science», en H. Tajfel y C. Fraser (eds.), Introducing Social Psychology, Harmondsworth, Penguin, pp. 1-53.

TODOROV, Tzvetan (1996): Facing the Extreme. Moral Life in the Concentration Camps, Weidenfeld \& Nicholson, London.

TRAVERSO, Enzo (2003): The Origins of Nazi Violence, The New Press, New York.

—, (2011): «La fábrica del odio. Xenofobia y racismo en Europa», El Viejo Topo, n. 285 , pp. $49-53$.

-, (2012): L'Histoire comme camp de bataille. Interpréter les violences du XXe siècle, La Découverte, París.

WATSON, Peter (2010): The German Genius, HarperCollins, New York.

WIMMER, Andreas y Nina Glick Schiller (2003): «Methodological Nationalism, the Social Sciences, and the Study of Migration: An Essay in Historical Epistemology», International Migration Review 37 (3), pp. 576-610.

YERUSHALMI, Yosef Hayim (2002): Zajor, la historia judía y la memoria judia, Anthropos, Barcelona.

ZWEIG, Stefan (2012): El mundo de ayer. Memorias de un europeo, El Acantilado, Barcelona. 